\title{
BMJ Open Treatment of patients with relapsed or refractory CD19+ lymphoid disease with T lymphocytes transduced by RV-SFG. CD19.CD28.4-1BBzeta retroviral vector: a unicentre phase I/II clinical trial protocol
}

Maria-Luisa Schubert, ${ }^{1}$ Anita Schmitt, ${ }^{1}$ Leopold Sellner, ${ }^{1,2}$ Brigitte Neuber, ${ }^{1}$ Joachim Kunz, ${ }^{3}$ Patrick Wuchter, ${ }^{4}$ Alexander Kunz, ${ }^{1}$ Ulrike Gern, ${ }^{1}$ Birgit Michels, ${ }^{1}$ Susanne Hofmann, ${ }^{1}$ Angela Hückelhoven-Krauss, ${ }^{1}$ Andreas Kulozik, ${ }^{3}$ Anthony D. Ho, ${ }^{1,2}$ Carsten Müller-Tidow, ${ }^{1,2}$ Peter Dreger, ${ }^{1,2}$ Michael Schmitt ${ }^{1,2}$

To cite: Schubert M-L, Schmitt A, Sellner L, et al. Treatment of patients with relapsed or refractory CD19+ lymphoid disease with $\mathrm{T}$ lymphocytes transduced by RV-SFG.CD19.CD28.41BBzeta retroviral vector: a unicentre phase $\mathrm{I} / \mathrm{Il}$ clinical trial protocol. BMJ Open 2019;9:e026644. doi:10.1136/ bmjopen-2018-026644

- Prepublication history and additional material for this paper are available online. To view these files, please visit the journal online (http://dx.doi. org/10.1136/bmjopen-2018026644).

Received 16 September 2018 Revised 15 February 2019 Accepted 20 March 2019

D) Check for updates

(c) Author(s) (or their employer(s)) 2019. Re-use permitted under CC BY-NC. No commercial re-use. See rights and permissions. Published by BMJ.

For numbered affiliations see end of article.

\section{Correspondence to}

Professor Michael Schmitt; michael.schmitt@med.uniheidelberg.de

\section{ABSTRACT}

Introduction Chimeric antigen receptor (CAR) T cells spark hope for patients with CD19+ B cell neoplasia, including relapsed or refractory $(r / r)$ acute lymphoblastic leukaemia (ALL) or r/r non-Hodgkin's lymphoma (NHL). Published studies have mostly used second-generation CARs with 4-1BB or CD28 as costimulatory domains. Preclinical results of third-generation CARs incorporating both elements have shown superiority concerning Iongevity and proliferation. The University Hospital of Heidelberg is the first institution to run an investigatorinitiated trial (IIT) CAR T cell trial (Heidelberg Chimeric Antigen Receptor T cell Trial number 1 [HD-CAR-1]) in Germany with third-generation CD19-directed CAR T cells. Methods and analysis Adult patients with $\mathrm{r} / \mathrm{r} \mathrm{ALL}$ (stratum I), r/r NHL including chronic lymphocytic leukaemia, diffuse large B-cell lymphoma, follicular lymphoma or mantle cell lymphoma (stratum II) as well as paediatric patients with r/r ALL (stratum III) will be treated with autologous T-lymphocytes transduced by third-generation RV-SFG.CD19.CD28.4-1BB zeta retroviral vector (CD19.CAR T cells). The main purpose of this study is to evaluate safety and feasibility of escalating

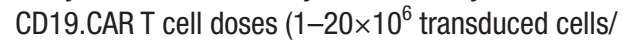
$\mathrm{m}^{2}$ ) after lymphodepletion with fludarabine (flu) and cyclophosphamide (cyc). Patients will be monitored for cytokine release syndrome (CRS), neurotoxicity, i.e. CART-cell-related encephalopathy syndrome (CRES) and/or other toxicities (primary objectives). Secondary objectives include evaluation of in vivo function and survival of CD19. CAR T cells and assessment of CD19.CAR T cell antitumour efficacy. HD-CAR-1 as a prospective, monocentric trial aims to make CAR T cell therapy accessible to patients in Europe. Currently, HD-CAR-1 is the first and only CAR T cell IIT in Germany. A third-generation Good Manufacturing Practice (GMP) grade retroviral vector, a broad spectrum of NHL, treatment of paediatric and adult ALL patients and inclusion of patients even after allogeneic stem cell transplantation (alloSCT) make this trial unique.
Strengths and limitations of this study

- First investigator-initiated trial with CAR T cells in Germany.

- Third-generation CD19-directed CAR construct incorporating both CD28 and 4-1BB.

- Broad spectrum of relapsed or refractory haematologic malignancies including acute lymphoblastic leukaemia, chronic lymphocytic leukaemia and lymphoma (diffuse large B-cell lymphoma, follicular lymphoma, mantle cell lymphoma), also including patients after allogeneic stem cell transplantation.

- CD19-negative relapses might occur after CD19directed CAR T cell therapy.

- Restriction to a single centre.

Ethics and dissemination Ethical approval and approvals from the local and federal competent authorities were granted. Trial results will be reported via peer-reviewed journals and presented at conferences and scientific meetings.

Trial registration number Eudra CT 2016-004808-60; NCT03676504; Pre-results.

\section{INTRODUCTION}

Treatment of patients with relapsed or refractory $(r / r)$ lymphoid malignancies including acute lymphoblastic leukaemia $(\mathrm{ALL})^{1}$ or chronic lymphocytic leukaemia (CLL) ${ }^{2-5}$ and other non-Hodgkin's lymphoma (NHL) such as diffuse large B cell lymphoma (DLBCL), ${ }^{6}$ follicular lymphoma (FL) ${ }^{7}$ or mantle cell lymphoma (MCL) ${ }^{8}$ remains a challenge. For patients with such $\mathrm{r} / \mathrm{r}$ CD19-positive malignancies, $\mathrm{T}$ cells genetically engineered to 
express chimeric antigen receptors (CARs) have shown remarkable results. ${ }^{9}$ Clinical responses in up to $81 \%-89 \%$ of paediatric ALL, ${ }^{11} 83 \%-88 \%$ of adult ALL, ${ }^{12} 13$ $57-71 \%$ of CLL ${ }^{1415}$ and $64 \%-82 \%$ of NHL ${ }^{16-19}$ have been reported for heavily pretreated patients following CAR T cells directed against CD19 (table 1).

CARs constitute synthetic receptors composed of three domains: (1) an extracellular antigen-specific target binding domain derived from an antibody's single-chain variable fragment $(\mathrm{scFv})$, (2) a hinge and transmembrane segment and (3) intracellular domain for intracellular signalling mediating activation and costimulation to the CAR-expressing $\mathrm{T}$ cell. First-generation CARs contain only the tyrosine-based $\zeta$-signal-transducing subunit from the TCR/CD3 receptor complex as intracellular domain, ${ }^{20}{ }^{21}$ whereas second-generation CARs carry costimulatory domains, for example, CD28, 4-1BB (CD137) or OX40 (CD134) adjacent to the $\zeta$ domain. Most widely, CD28 and 4-1BB costimulatory domains have been used. Both have shown to enhance CAR T cell activity and signalling and to mediate complete responses in patients with advanced CD19-positive haematologic malignancies. ${ }^{162-24}$ Third-generation CARs including two costimulatory molecules within their constructs, that is, CD28 and 4-1BB, have demonstrated superior proliferative capacity, a more robust survival and antitumour response in vitro and in vivo compared with second-generation CARs comprising either CD28 or $4-1 B B .{ }^{25-27}$ In ALL and lymphoma patients co-infused with second-generation and third-generation CD19-directed CARs, significantly superior engraftment, a 23-fold higher expansion and prolonged in vivo persistence of third-generation CAR T cells was reported. ${ }^{28}$

In Europe, almost all clinical CAR $\mathrm{T}$ cell trials are industry-driven. The University Hospital of Heidelberg is currently the first institution in Germany to run an investigator-initiated trial (IIT) phase I/II CAR T cell trial (Heidelberg Chimeric Antigen receptor T cell Trial number 1 [HD-CAR-1]; EudraCT-No. 2016-004808-60; NCT03676504 (clinicaltrials.gov); federal authority No.: 3148/02; Institutional review board/Ethics Committee approval No.: AF-mu 405/2017); HD-CAR-1 clinical trial protocol version 03; date 22 June 2018; for HD-CAR-1 protocol synopsis, see online supplementary file 1). This monocentric, open-label, prospective clinical trial initiated in September 2018 treats adult patients with $\mathrm{r} / \mathrm{r}$ ALL, $\mathrm{r} / \mathrm{r}$ CLL or other NHL including DLBCL, FL or MCL as well as paediatric patients with $\mathrm{r} / \mathrm{r}$ ALL with autologous $\mathrm{T}$ lymphocytes transduced with a third-generation CAR retroviral vector targeting CD19 (RV-SFG. CD19.CD28.4-1BBzeta) in-house.

\section{METHODS AND ANALYSIS}

\section{Study design of HD-CAR-1}

The study consists of three different patient strata with confirmed CD19+ (by immunohistochemistry or flow cytometry [FACS]) lymphoid disease: (1) r/r adult ALL patients (stratum I), (2) $\mathrm{r} / \mathrm{r}$ adult patients with NHL (CLL, DLBCL, FL or MCL; stratum II) and (3) r/r paediatric ALL patients (stratum III).

Autologous $\mathrm{T}$ lymphocytes transduced with the RV-SFG.CD19.CD28.4-1BBzeta retroviral vector (CD19. CAR $T$ cells) are administered in three dose levels per stratum: $1 \times 10^{6} \mathrm{CD} 19$.CAR T cells $/ \mathrm{m}^{2}$ (dose level 1 [D1]), $5 \times 10^{6} \mathrm{CD} 19$.CAR T cells $/ \mathrm{m}^{2}$ (dose level 2 [D2]), and $20 \times 10^{6} \mathrm{CD} 19$.CAR T cells $/ \mathrm{m}^{2}$ (dose level 3 [D3]). Three to 16 patients per stratum leading to a maximum of 48 patients will be treated in order to assess safety and maximum tolerated dose of CD19.CAR T cells (figure 1).

Following enrolment (exclusion and inclusion criteria summarised in box 1), patients undergo leukapheresis for collection of peripheral blood mononuclear cells (PBMCs). PBMCs are transduced with the RV-SFG. CD19.CD28.4-1BBzeta retroviral vector (provided by Malcolm Brenner, Baylor College of Medicine, Houston, Texas, USA) after activation with anti-CD3 and anti-CD28 antibodies (MACS GMP Pure, Miltenyi Biotec, Bergisch Gladbach, Germany) and culturing with IL-7 (10 ng/mL) and IL-15 (5 ng/mL) (CellGenix, Freiburg, Germany) at the Good Manufacturing Practice (GMP) Core Facility of the Internal Medicine V Department of the University Hospital Heidelberg. RV-SFG.CD19.CD28.4-1BBzeta carries an anti-CD19 scFv derived from the FMC63 antibody inserted to the SFG retroviral backbone. ${ }^{29}$ The transmembrane domain is derived from $\mathrm{CD} 28$, the hinge domain from the human $\mathrm{IgG}_{1}-\mathrm{CH}_{2} \mathrm{CH}_{3}$ domain $^{30}$ and $4-1 \mathrm{BB}$ is inserted between the $\mathrm{CD} 28$ and $\mathrm{CD} 3 \zeta$ domains (figure 2).

All patients receive lymphodepleting chemotherapy with fludarabine (flu) $30 \mathrm{mg} / \mathrm{m}^{2} /$ day and cyclophosphamide (cyc) $500 \mathrm{mg} / \mathrm{m}^{2} /$ day on days -4 to -2 (ie, 3 days) prior to CD19.CAR T cell infusion (defined as day 0 ) in an in-patient setting (figure 3).

CAR T cells are administered only to patients who have consented to study participation and fulfil the following requirements: (1) no evidence of serious infection (active infection with positive blood cultures for bacteria, fungus or virus within 48 hours of CD19.CAR T cell infusion); (2) adequate renal function defined as serum creatinine of $\leq 2 \mathrm{x}$ ULN or eGFR $\geq 30 \mathrm{~mL} /$ minute $/ 1.73 \mathrm{~m}^{2}$; (3) no evidence of significant cardiac dysfunction; (4) no evidence of significant pulmonary dysfunction and (5) no acute neurological toxicity >grade 1 (with the exception of peripheral neuropathy). Should an event prohibit the administration of CD19.CAR T cells, the infusion must be delayed until the event resolves. If CD19.CAR T cell administration is delayed for more than 2 weeks, conditioning chemotherapy must be repeated.

Dose escalation of CD19.CAR T cells (dose 1-3; D1-D3) is performed according to a classical $3+3+4$ design. Stratum I and II (adult ALL and CLL/NHL patients) recruitments are performed independently, and occurrence of dose-limiting events in one of these strata will not affect recruitment of the other one. The first cohort of three patients in stratum I and stratum II is treated with 


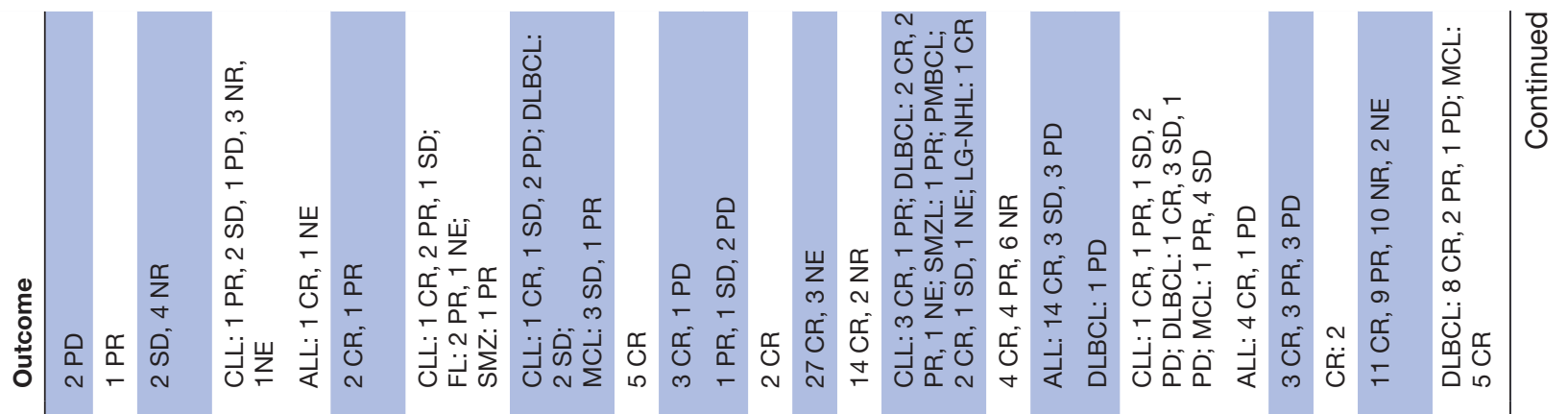

章产

$\stackrel{\infty}{\sim} \stackrel{\infty}{\sim} \stackrel{\infty}{\sim}$

\section{$\stackrel{\infty}{0 ָ}$}

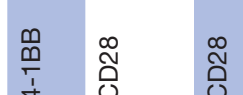

รูํำ

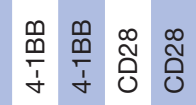

$\infty$
$\stackrel{\infty}{\infty} \underset{\sim}{+}$
$\stackrel{\sim}{0}$

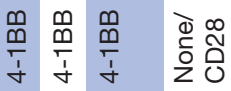




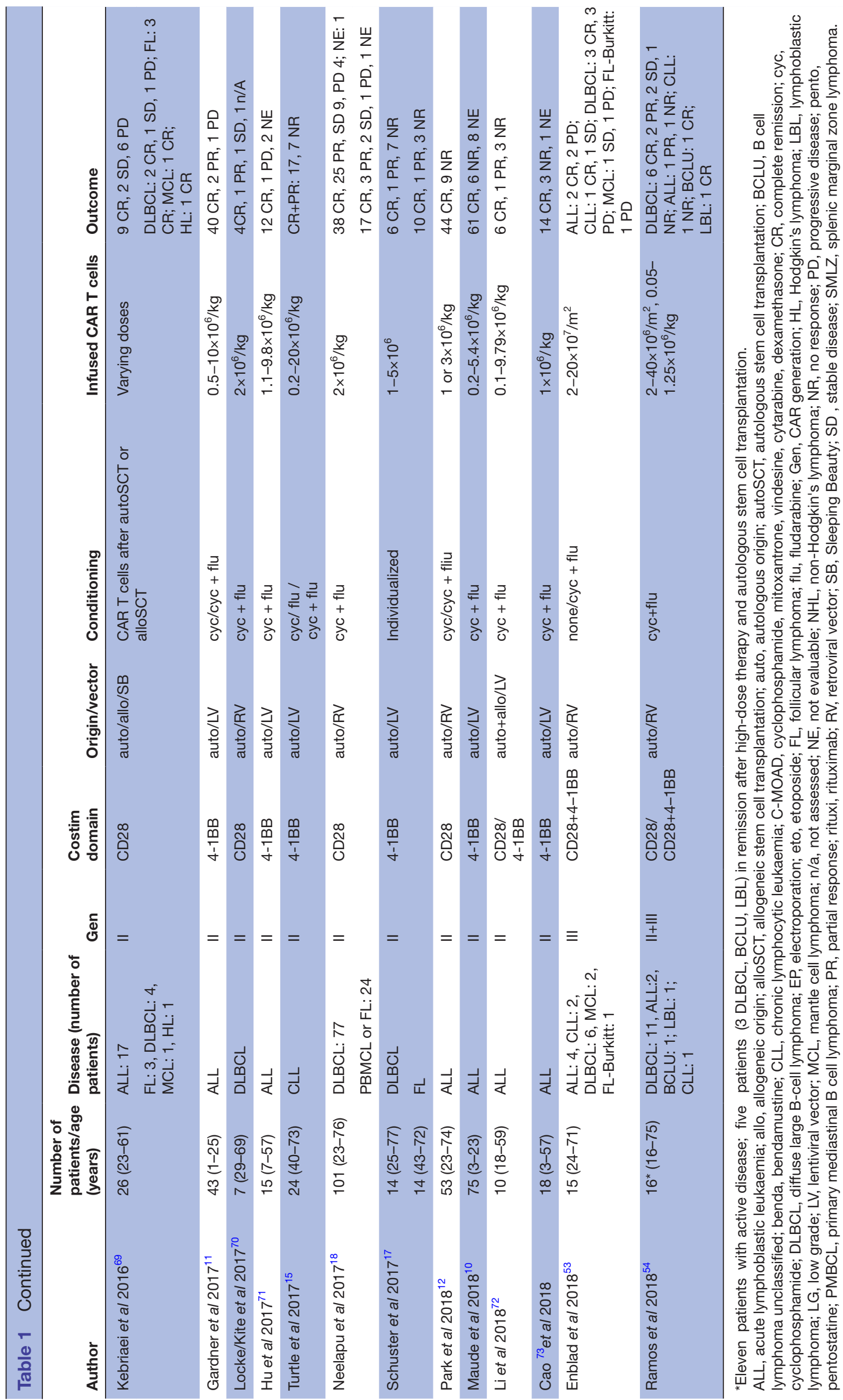




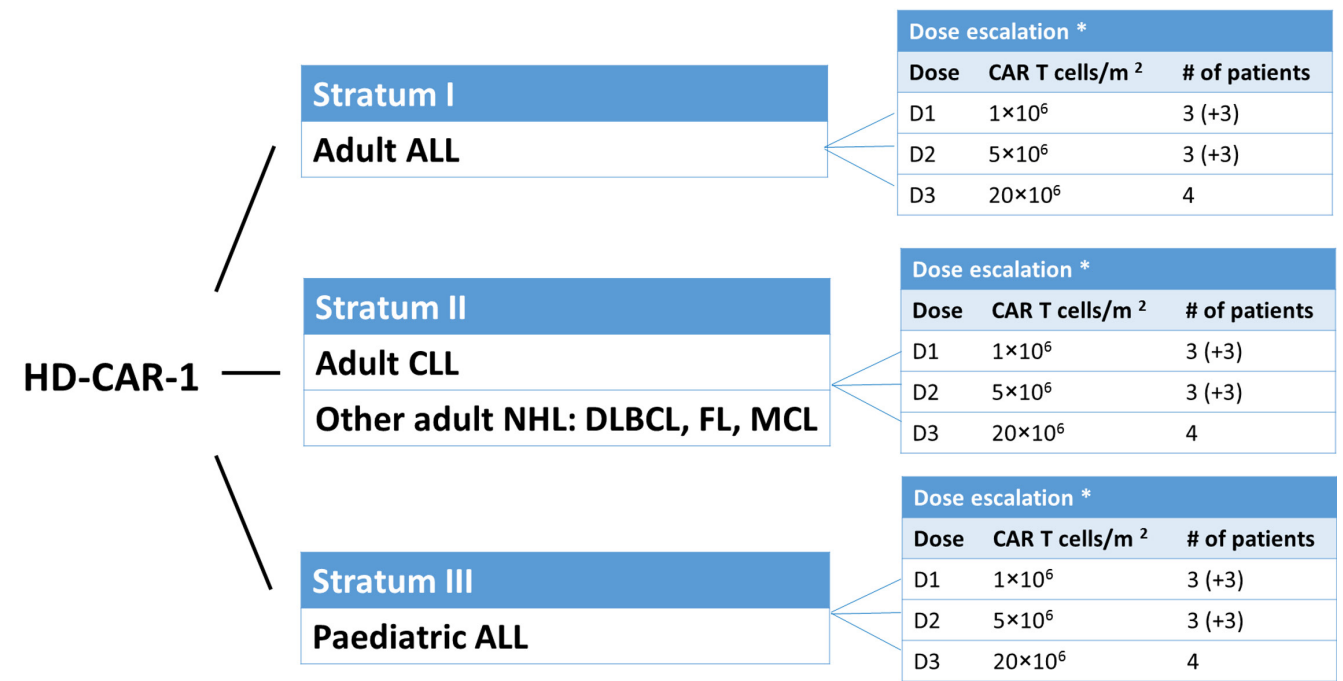

Figure 1 HD-CAR-1 treatment strata. *Dose escalation design of HD-CAR-1 is performed according to a classical $3+3+4$ design. Stratum I and II (adult ALL and CLL/NHL) are recruited independently. Occurrence of dose-limiting events in one of these strata does not affect recruitment of the other one. The first cohort of three patients in stratum I and stratum II is treated with CD19.CAR T cells at dose level (D) 1. Between treatments of individual patients, a waiting period of at least 28 days is mandatory. If any of the first three patients displays DLT, three more patients are enrolled at D1. If less than three DLTs occur in this group of six patients, the study continues to D2. The same scheme is applied to progress towards D3. Initiation of stratum III (children and adolescents with $r / r$ ALL) is performed after completion of D1 in stratum I or II without evidence of DLT in the first three patients, or with $\leq 2$ DLT in the first six patients. If more than two patients display DLT at D1, D2 or D3, the DMC will be advised. An interim evaluation by the DMC is mandatory after completion of D1 and D2. ALL, acute lymphoblastic leukaemia; CLL, chronic lymphocytic leukaemia; D, dose level; DLBCL, diffuse large B cell lymphoma; DLT, dose-limiting toxicity; DMC, Data Monitoring Committee; FL, follicular lymphoma; HD-CAR-1, Heidelberg Chimeric Antigen Receptor T cell Trial number 1; MCL, mantle cell lymphoma; NHL, non-Hodgkin's lymphoma.

CD19.CAR T cells at dose level 1. Between treatments of individual patients, a waiting period of at least 28 days is mandatory. If any of the first three patients displays dose-limiting toxicity (DLT), additional three patients

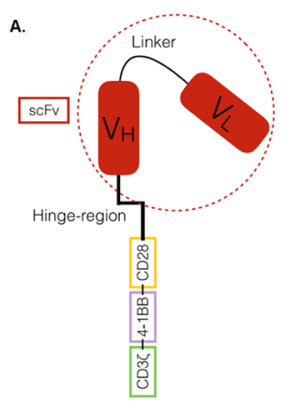

B.

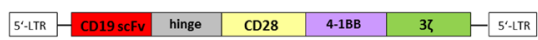

Figure 2 Structure of the HD-CAR-1 CAR. (A) Structure of the third-generation CAR construct used in the HDCAR-1 trial. The CAR is composed of an extracellular antigen-specific scFv molecule derived from the IgG2a mouse monoclonal antibody FMC63. The scFv is attached via a flexible hinge region from the human $\lg \mathrm{G} 1-\mathrm{CH}_{2} \mathrm{CH}_{3}$ domain to the CD28-derived transmembrane. This, in turn, is attached to the cytoplasmic receptor portion. The intracellular signalling domain originates from the stimulatory $\mathrm{CD} 3 \zeta$-chain of a T cell receptor. In the third-generation HDCAR-1 construct, costimulation is mediated by the CD28 and 4-1BB domains. (B) Linear representation of RV-SFG.CD19. CD28.4-1BBzeta. HD-CAR-1, Heidelberg Chimeric Antigen Receptor T cell Trial number 1; scFv, single-chain variable fragment. are enrolled at dose level 1. If less than three DLTs occur in this group of six patients, the study continues to dose level 2. The same scheme is applied for progressing to dose level 3. Initiation of stratum III (children and adolescents with $\mathrm{r} / \mathrm{r}$ ALL) occurs after completion of dose level 1 in stratum I or II without evidence of DLT in the first three patients, or with $\leq 2$ DLT in the first six patients. If more than two patients display DLT at dose level 1, 2 or 3, the Data Monitoring Committee (DMC) is advised. An interim evaluation by the DMC is mandatory after completion of dose level 1 and 2. All patients who have received CD19.CAR $\mathrm{T}$ cells are included in the safety analysis. Patients will be excluded from the per protocol population if the patients are lost to follow-up before completion of 3 weeks post-CAR $\mathrm{T}$ cell administration. In these cases, new patients are recruited to fill the cohorts and assure that each cohort reaches the minimum patient numbers to finalise according to protocol. If a patient does not attend a trial visit, reasons should be clarified. All efforts have to be made to follow up the patient. In cases where a patient is lost to follow-up, reasonable efforts must be made by the study site personnel to contact the patient and determine the reason for withdrawal.

\section{Endpoints}

Primary endpoints of HD-CAR-1 include safety and feasibility: regarding safety, frequency and grade of cytokine release syndrome (CRS), neurotoxicity (CAR-T-cell-related encephalopathy syndrome (CRES)) and other 
Box 1 Inclusion and exclusion criteria of HD-CAR-1

\section{Stratum I-II (Adults)}

Inclusion criteria

- Confirmed CD19+ ALL, CLL, DLBCL, FL or MCL in patients $\geq 18$ years

- ALL: Confirmed CD19+ ALL (Philadelphia [Ph]+and Ph-) by cytology and FACS AND

- Relapsed or refractory disease (including 'molecular relapse' with MRD levels $>10^{-3}$ at two occasions $>2$ weeks apart) with confirmed CD19expression on malignant cellsAny relapse after alloSCT ( $\geq 6$ months from alloSCT at the time of CAR T cell infusion) OR

- Any relapse failing to achieve an MRD level of $<10^{-3}$ after $\geq 2$ lines of treatment $O R$

- Primary refractory as defined by not achieving a CR after $\geq 2$ lines of treatment

$>$

- CLL/NHL: Confirmed CD19+ CLL/NHL (including CLL, DLBCL, FL or MCL)

CLL in need of treatment with

1. Early relapse (within 2 years) after end of chemoimmunotherapy or chemoimmunotherapy refractoriness plus failure or intolerance of both BTK and BCL2 inhibitors OR

2. Relapse after alloSCT, ineligible for or refractory to standard interventions (DLI, CD20 antibodies, chemoimmunotherapy)

DLBCL with

1. Refractoriness to a second or later line of chemoimmunotherapy $O R$

2. Relapse after autoSCT plus ineligibility for alloSCT (including refractoriness to one line of salvage chemoimmunotherapy) $O R$

3. Relapse after alloSCT

$\mathrm{FL}$ in need of treatment with

1. Relapse $<2$ years after chemoimmunotherapy AND ineligibility for or failure of autoSCT AND ineligibility for or failure of idelalisib OR

2. Relapse after alloSCT, ineligible for or refractory to standard interventions (donor lymphocyte infusions, CD20 antibodies, chemoimmunotherapy) MCL with

1. Relapse after standard first-line therapy AND ineligibility for or failure to BTKi salvage therapy $O R$

2. Relapse after alloSCT AND ineligibility for or failure to BTKi salvage therapy

- Measurable disease/MRD at the time of enrollment

Life expectancy $\geq 12$ weeks

- ECOG performance status $\leq 2$ at the time of screening

- Adequate organ functionRenal function defined as serum creatinine of $\leq 2$ times ULN or eGFR $\geq 30 \mathrm{~mL} /$ minute $/ 1.73 \mathrm{~m}^{2}$

- Liver function defined asALT $\leq 5$ times the ULN for the respective age

- Bilirubin $\leq 2.0 \mathrm{mg} / \mathrm{dL}$ with the exception of patients with hyperbilirubinemia explained by Gilbert-Meulengracht syndrome (may be included if total bilirubin is $\leq 3.0 x$ ULN and direct bilirubin $\leq 1.5 x$ ULN) or extrahepatic disease (eg, chronic haemolytic anaemia)

- Minimum level of pulmonary reserve defined as $\leq$ grade 1 dyspnoea and pulse oxygenation $>90 \%$ on room air

- Haemodynamic stability and LVEF $\geq 40 \%$ as confirmed by echocardiogram

- ANC $\geq 500 / \mathrm{mm}^{3}$

- ALC $\geq 100 / \mathrm{mm}^{3}$

- Women of childbearing potential (defined as all women physiologically capable of becoming pregnant) and all male participants must agree to use highly effective methods of contraception for 1 year following CD19.CAR T cell therapy

- Ability to understand the nature of the trial and the trial-related procedures

Written informed consent must be obtained prior to any screening procedures

Exclusion criteria

- The following medications are excluded:

- Immunosuppressive medication with the exception of $\leq 30 \mathrm{mg}$ prednisolone/d or equivalent at the time of CAR T cell transfusion

- Bridging/maintenance therapy including chemotherapy and immunotherapy must be stopped $\geq 2$ weeks prior to leukapheresis, but can be continued between leukapheresis and lymphodepletion

- Intrathecal chemotherapy is possible at any time, but not during lymphodepletion until 14 days after CD19.CAR T cell transfusion

- Any DLI must be completed $>6$ weeks prior to CD19.CAR T cell infusion

- Florid/acute or chronic GvHD

- Uncontrolled active hepatitis B or C

- HIV-positivity

- Uncontrolled acute life-threatening bacterial, viral or fungal infection

- Severe concomitant disease (eg, uncontrolled arterial hypertension, heart failure NYHA III-IV, uncontrolled diabetes mellitus and uncontrolled hyperlipidaemia)

- Unstable angina and/or myocardial infarction within 3 months prior to screening

- Any previous or concurrent malignancy

- The following exceptions do not constitute exclusion criteria:

- Adequately treated basal cell or squamous cell carcinoma (adequate wound healing is required prior to study entry)

- In situ carcinoma of the cervix or breast, treated curatively without evidence of recurrence $\geq 3$ years prior to the study 


\section{Box 1 Continued}

- CLL or FL transformed into an aggressive B cell lymphoma

- A primary malignancy which is in complete remission for $\geq 5$ years

- Pregnant or nursing (lactating) women

Intolerance to the excipients of the cell product

- Active CNS involvement in ALL patients at the time of screening is not an exclusion criterion, but patients with CNS 3 status at clinical screening (d-14) are not eligible for CD19.CAR T cell transfusion

- Participation in another clinical trial at the time of screening

Stratum III (Children and adolescents with ALL)

Inclusion criteria

- Age of $>3$ years until $<18$ years at the time of screening

- $\mathrm{CD} 19^{+} \mathrm{ALL}(\mathrm{Ph}+$ and Ph-) confirmed by cytology and FACS AND

- Relapsed or refractory disease (including 'molecular relapse' with PCR-MRD $>10^{-3}$ at two occasions $>2$ weeks apart) with confirmed CD19-expression on malignant cells

- Any relapse after alloSCT ( $\geq 6$ months from alloSCT at the time of CAR T cell infusion) OR

- Any relapse failing to achieve an MRD level of $<10^{-3}$ after $\geq 2$ lines of treatment $O R$

- Primary refractory as defined by not achieving a CR after $\geq 2$ lines of treatment

- Measurable disease/MRD at the time of enrollment

- Life expectancy $\geq 12$ weeks

- ECOG performance status $\leq 2$ (age $\geq 16$ years) or Lansky performance status $\geq 50$ (age $<16$ years) at the time of screening

- Adequate organ function

- Renal function defined as serum creatinine clearance $\geq 30 \mathrm{~mL} /$ minute $/ 1.73 \mathrm{~m}^{2}$

- Liver function defined as

- ALT $\leq 5$ times the ULN for the respective age

- Bilirubin $\leq 2.0 \mathrm{mg} / \mathrm{dL}$ with the exception of patients with hyperbilirubinaemia explained by Gilbert-Meulengracht syndrome or extrahepatic disease (eg, chronic haemolytic anaemia)

- Minimum level of pulmonary reserve defined as $\leq$ grade 1 dyspnoea and pulse oxygenation $>90 \%$ on room air

- Haemodynamic stability and LVEF $\geq 40 \%$ or shortening fraction $>29 \%$ as confirmed by echocardiogram

- ANC $\geq 500 / \mathrm{mm}^{3}$

- $A L C \geq 100 / \mathrm{mm}^{3}$

- Women of childbearing potential (defined as all women physiologically capable of becoming pregnant) and postpubertal male participants must agree to use highly effective methods of contraception for 1 year following CD19.CAR T cell therapy

- Written informed consent of the study patient and/or the legal representative must be obtained prior to any screening procedures

Exclusion criteria

- The following medications are excluded:

- Immunosuppressive medication with the exception of $<0.5 \mathrm{mg} / \mathrm{day}^{*} \mathrm{~kg}$ BW prednisolone-equivalent at the time of CD19.CAR T cell transfusion

- Bridging/maintenance therapy including chemotherapy and immunotherapy must be stopped $\geq 2$ weeks prior to leukapheresis, but can be continued between leukapheresis and lymphodepletion

- Intrathecal chemotherapy is possible at any time, but not during lymphodepletion until 14 days after CD19.CAR T cell transfusion

- Any DLI must be completed $>6$ weeks prior to CD19.CAR T cell infusion

- Florid/acute or chronic GivHD

- Uncontrolled active hepatitis B or C

- HIV-positivity

- Uncontrolled acute life-threatening bacterial, viral or fungal infection

- Severe concomitant disease (eg, any life-limiting genetic disorder). Patients with down syndrome will not be excluded

- Any previous or concurrent malignancy

- The following exceptions do not constitute exclusion criteria:

- Lymphoblastic lymphoma transformed into a $\mathrm{CD} 19^{+}$acute lymphoblastic leukaemia

- A primary malignancy which is in complete remission for $\geq 5$ years

- Pregnant or nursing (lactating) women

Intolerance to the excipients of the cell product

- Active CNS involvement at the time of screening is not an exclusion criterion, but patients with CNS 3 status at clinical screening (d-14) are not eligible for CD19.CAR T cell transfusion

- Participation in another clinical trial at the time of screening

ALC, absolute lymphocyte count; ALL, acute lymphoblastic leukaemia; alloSCT, allogeneic stem cell transplantation; ALT, alanine aminotransferase; ANC, absolute neutrophil count; autoSCT, autologous stem cell transplantation; CLL, chronic lymphocytic leukaemia; CNS, central nervous system; CR, complete remission; DLBCL, diffuse large B-cell lymphoma; DLI, donor lymphocyte infusions; ECOG, Eastern Cooperative Oncology Group; eGFR, estimated glomerular filtration rate; FACS, flow cytometry; FL, follicular lymphoma; GVHD, Graft-versus-Host disease; HD-CAR-1, Heidelberg Chimeric Antigen Receptor T cell Trial number 1; LVEF, left ventricular ejection fraction; MCL, mantle cell lymphoma; MRD, minimal residual disease; NHL, non-Hodgkin's lymphoma; ULN, upper limit of normal. 


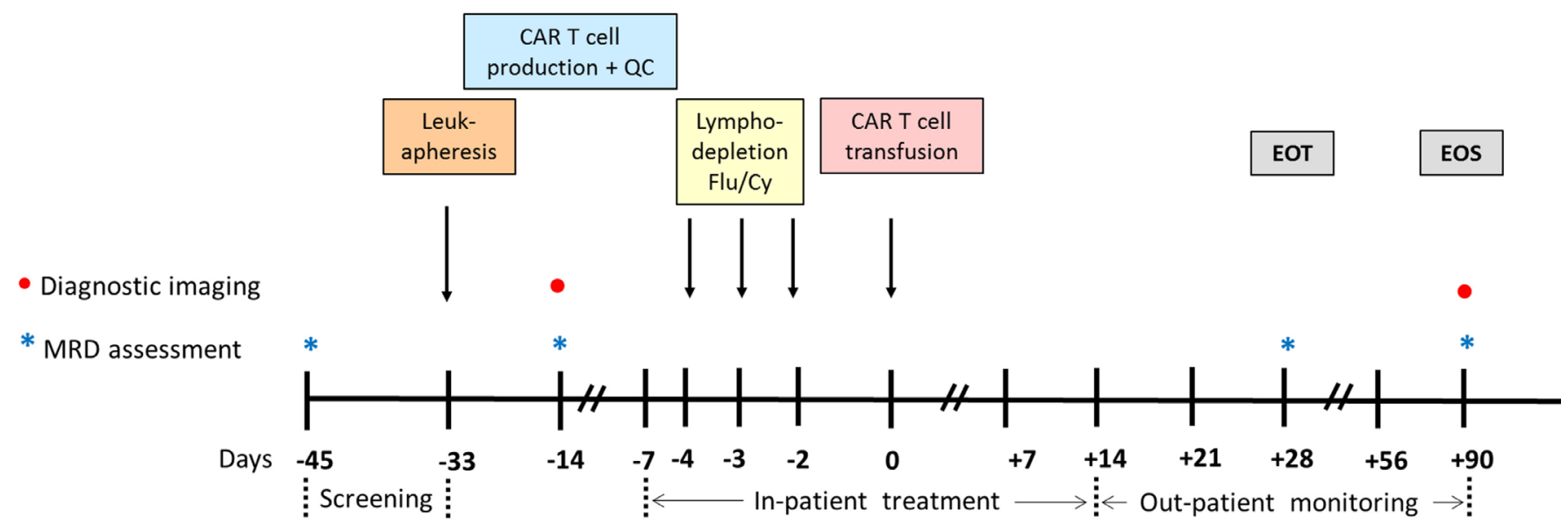

Figure 3 HD-CAR-1 clinical trial: general time schedule. After inclusion, patients undergo leukapheresis followed by CAR T cell production. After clearance of QC of the CD19.CAR T cell product, patients receive a preconditioning therapy consisting of fludarabine (flu) $30 \mathrm{mg} / \mathrm{m}^{2} /$ day and cyclophosphamide (cy) $500 \mathrm{mg} / \mathrm{m}^{2} /$ day (day -4 to day -2 ) followed by a rest day on day -1 . Patients receive CD19.CAR T cells intravenously on treatment day 0. CD19.CAR T cell infusion is followed by at least 14 days of in-patient observation. This period is followed by out-patient monitoring with EOT on day 28 and EOS on day 90 after CD19. CAR T cell administration. EOS, end-of-study; EOT, end-of-treatment; HD-CAR-1, Heidelberg Chimeric Antigen Receptor T cell Trial number 1; MRD, minimal residual disease; QC, quality control.

adverse events (AEs) will be assessed. CRS will be graded according to adapted grading criteria proposed by Lee $e t \mathrm{al}$ $2014^{31}$ and Davila et al $2014^{13}$ (online supplementary table 1.A and B). Grading of CRESwill be assessed according to the Common Terminology Criteria for Adverse Events (CTCAEV.5.0) and an orientating 10-point examination (online supplementary table 1.C). Management of CRS and CRES is summarised in online supplementary figure 1 and 2. Other toxicities are assessed according to CTCAEV.5.0.

DLT is defined as any AE that is not (1) pre-existing or due to (2) the underlying malignancy. CRS and neurotoxicity are considered as DLT if $\geq$ grade 4 . Non-haematologic DLT is any grade 3 or higher toxicity (according to CTCAEv5.0) occurring within 90 days after CD19.CAR $\mathrm{T}$ cell administration. Haematologic DLTs are defined as any grade 4 (except lymphopaenia) toxicity (according to CTCAEv5.0) lasting $>30$ days. Patients with evidence of bone marrow disease are not evaluable for haematologic DLT. The following toxicities are not considered DLTs: laboratory tumour lysis syndrome (TLS) and grade 1 clinical TLS according to the Cairo and Bishop classification, ${ }^{32}$ hypoalbuminaemia, transient $(<72$ hours) grade 4 hepatic enzyme abnormality and/or grade 3 or 4 fever or neutropenic fever.

With regards to feasibility, successful transduction and manufacturing of respective doses of CD19.CAR T cells are assessed. Manufacturing failure is considered if $<50 \%$ of the intended CD19.CAR $\mathrm{T}$ cell dose could be produced. CD19.CAR T cells are not administered in case of (1) serious infection, (2) impaired renal, cardiac or pulmonary dysfunction or (3) signs of neurological toxicity >grade 1 (with the exception of peripheral neuropathy).
Secondary endpoints include monitoring of survival and function of CD19. CAR T cells in treated patients. Detection of CD19.CAR T cells will be performed by quantitative PCR. Additionally, evaluation of antitumour efficacy of CD19.CAR T cells in patients at day 90 (end-ofstudy [EOS]) after CD19.CAR T cell infusion (overall response rate, complete remission [CR], partial response $[\mathrm{PR}]$ ) is assessed. Furthermore, time to response (at least PR), duration of overall response (DOR), progression-free survival (PFS) and overall survival (OS) after CD19.CAR T cell transfusion are determined. Statistical analysis is performed via descriptive methods: for primary endpoint analysis, summary tables display the number of patients observed with AEs according to CTCAE, as well as frequency and grade of CRS and CRES . All secondary endpoint variables are analysed using explorative and mainly descriptive methods. Summary statistics for categorical variables will include frequency counts and percentages.

\section{Data collection, handling, management and monitoring}

Patients are evaluated as outlined in the study calendar (table 2). All data are documented on case report files (CRFs). Patient data are documented pseudonymously. The investigator, or a designated representative, completes the CRF forms as soon as possible after the information is collected. Explanation should be given for all missing data. All entries in the CRF must be verifiable by source documents. The investigator is responsible for ensuring that all forms of the CRF are completed correctly and that entries can be verified against source data. The $\mathrm{CRF}$ /database must contain a full audit trail, in order to make all changes applied to the data after their first entry reproducible. To ensure data quality, regular monitoring 


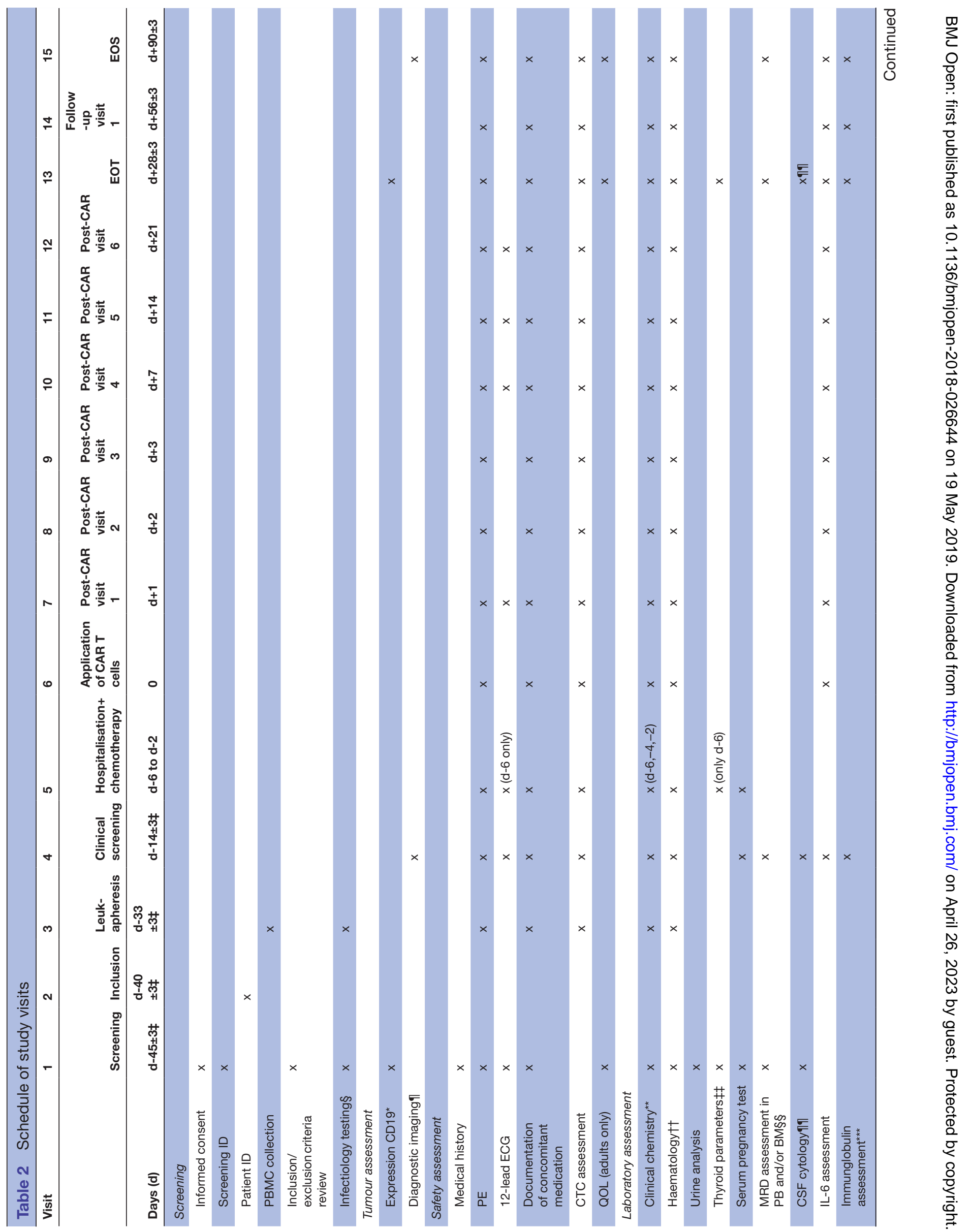




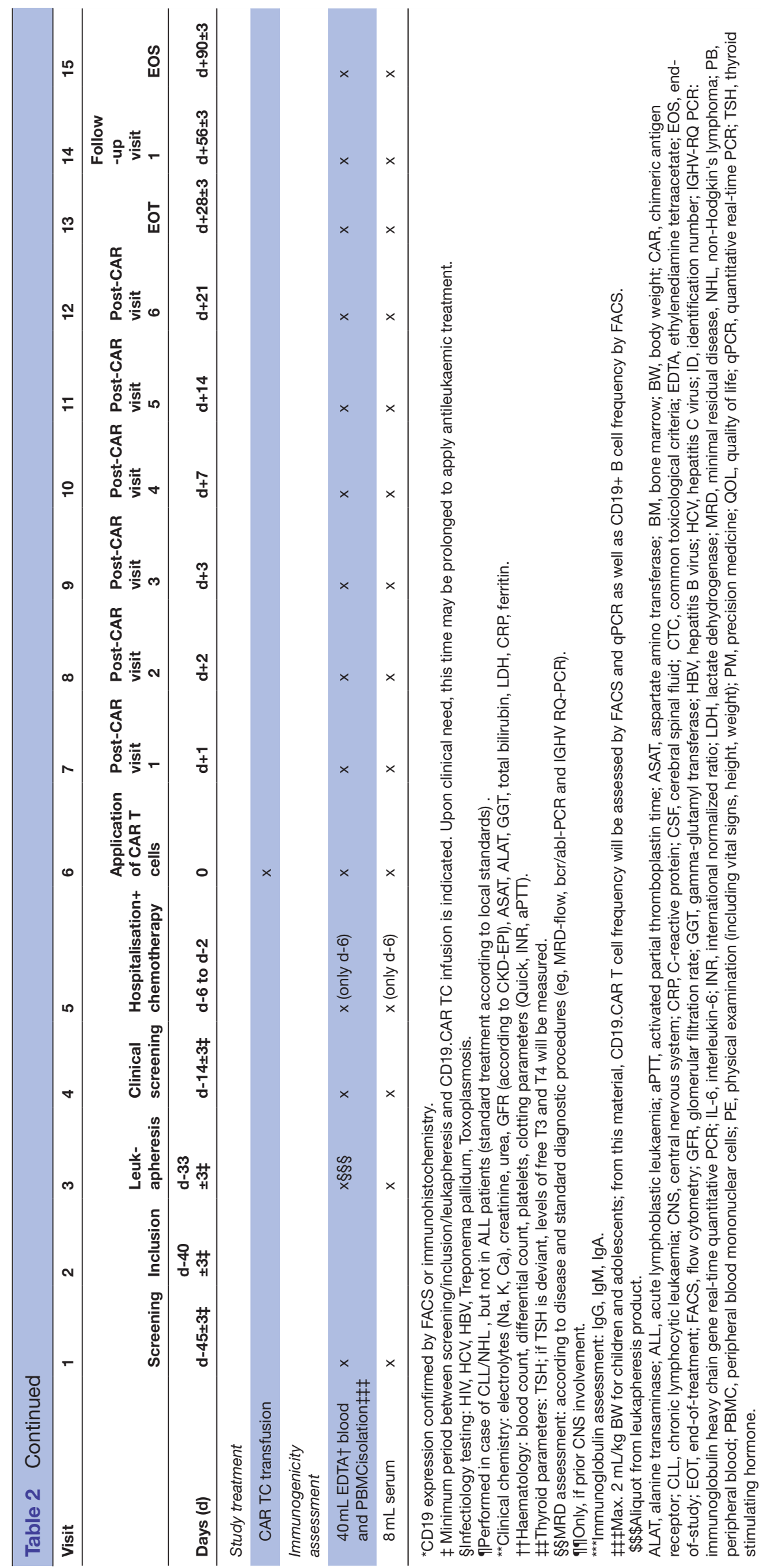


of the data entry will be done at site by an independent clinical monitor (CONVIDIA clinical research $\mathrm{GmbH}$ ). The monitor surveys completeness, validity and plausibility of data. Missing data or inconsistencies will be reported back to the trial centre and have to be clarified by the responsible investigator prior to database lock. If no further corrections are to be made in the database after completion of the trial, it will be declared locked and used for statistical analysis.

The clinical study centre of the Medizinische Klinik V of the University Hospital Heidelberg is responsible for archiving the Trial Master File (TMF) including the trial protocol, CRFs, written opinions on the protocol and procedures, final reports, audit certificates and all other relevant documents in accordance to the International Council on Harmonisation of Technical Requirements for Registration of Pharmaceuticals for Human Use Harmonized Tripartite Guideline on Good Clinical Practice (GCP) (as effective by 14 June 2017).

Serious adverse event (SAE) must be reported to the clinical monitor within 24 hours after the SAE becomes known using a defined SAE form. If new information on the risk-to-benefit ratio is obtained and safety concerns arise, the sponsor reserves the right to interrupt or terminate the trial. The investigators can recommend interruption or termination of the study or of treatment arms based on the results of the intermittent SAE evaluation or of accumulating information on abovementioned reasons. The ethics committee (EC) and the competent authorities will be informed about the premature closure of the trial or one of the treatment arms. Furthermore, the EC and competent authorities themselves may decide to stop or suspend the trial. All involved investigators have to be informed immediately about a cessation/ suspension of the trial. The decision is binding to the trial centre and involved investigators. According to $\$ 40$ German Drug Law (AMG), an insurance policy is effective (Ecclesia $\mathrm{GmbH}$ ) covering for harm or injuries caused to participating patients by the trial and arising out of this research.

Data monitoring is performed by on-site and off-site visits from the independent clinical monitor. The investigator must allow the monitor to verify all essential documents and must provide support at all times to the monitor. Regulatory authorities and/or auditors authorised by the sponsor may request access to all source documents, CRFs and other trial documentation. DMC acts according to the Data Monitoring Charter. DMC meets periodically to review summarised and individual patients data related to safety, data integrity and overall conduct of the trial and review specific interim analyses for safety and/or efficacy, as appropriate . Additionally, DMC provides recommendations to continue as originally planned, change or terminate the trial depending on these analyses, communicate other recommendations or concerns as appropriate and operate according to the procedures described in the Data Monitoring Charter. DMC members defined in the HD-CAR-1 clinical trial protocol and Data Monitoring Charter are individuals who are impartial and independent of the investigators and the sponsor and who have no financial, scientific or other conflict of interest with the study. As soon as data regarding 1 month PFS for the first three patients are available, interim analyses by the DMC is performed. Results are disseminated inside or outside the study team.

\section{Confidentiality and access to data}

Confidentiality of trial data is provided according to the European Datenschutz-Grundverordnung (DSGVO) and the German Bundesdatenschutzgesetz. The data obtained in the course of the trial will be treated pursuant to the Federal Data Protection Law (Bundesdatenschutzgesetz, BDSG). During the clinical trial, enrolled patients are identified solely by means of their individual identification code (subject number, randomisation number). Trial findings stored in a computer are stored in accordance with local data protection law and will be handled with strictest confidentiality. The appropriate regulations of local data legislation are fulfilled in its entirety. The principal investigator and the study physicians will directly and personally obtain consent and assent from enrolled patients. Each enrolled patient consents via written informed consent to allow access to his/her original medical records for trial-related monitoring, audit and regulatory inspection. Authorised persons (clinical monitors, auditors, inspector) may inspect patient-related data collected during the trial ensuring the data protection law. The investigator maintains a patient identification list to enable records to be identified. Clinical trial protocol, CRFs, other results forms and laboratory data are not disclosed to third parties. Staffs of the investigators involved in the trial are bound by this agreement.

\section{Protocol amendments}

All planned substantial changes to the clinical trial protocol are submitted to the EC and the competent authority in writing as protocol amendments. They have to be signed by the sponsor and approved by the EC and the competent authority.

\section{Patient and public involvement}

Patients and public were not involved in research preceding this study. They were not involved in the design, recruitment or conduction of this trial.

\section{Ethics and dissemination}

HD-CAR-1 clinical trial will be conducted according to the principles of the Declaration of Helsinki (2008). Written informed consent will be taken from all participants, and confidentiality and anonymity of patients granted in accordance to German general national regulatory requirements, that is, the Bundesdatenschutzgesetz (BDSG). After completion of the trial, HD-CAR-1 participants, physicians, the public and other relevant groups will be informed of the study results via peer-reviewed journal publications, presentation of results at relevant conferences as well as scientific meetings. 


\section{DISCUSSION}

\section{Why do we need CARs?}

Treatment of B cell malignancies has significantly improved in the last decades. Children and adolescents diagnosed with B-ALL and treated with conventional treatment display cure rates of about $90 \% .^{33}$ However, prognosis declines dramatically in adult ALL or $\mathrm{r} / \mathrm{r}$ childhood ALL: adult ALL patients display OS rates of $<50 \%{ }^{34}$ and paediatric patients with refractory ALL not reaching CR with negative minimal residual disease (MRD) have survival rates of $<10 \% .^{35}$

Treatment for patients with CLL and other NHL has also improved, particularly due to the $\mathrm{B}$ cell receptor inhibitors ibrutinib (BTK inhibitor) and idelalisib (PI3K inhibitor) as well as the BCL2 inhibitor venetoclax. ${ }^{36-39}$ However, CLL patients with failure to ibrutinib ${ }^{3}$ or idelalisib $^{40}$ and ineligible or refractory to venetoclax ${ }^{2}$ have a very poor outcome. DLBCL patients with resistance to primary and salvage chemotherapy or relapse within 12 months following autologous SCT display median OS of only 6 months. ${ }^{6}$ Also, patients with FL refractory to chemoimmunotherapy and disease progression under idelalisib have 2-year median survival rates of only $22 \%{ }^{7}$ With regards to relapsed MCL, treatment is often ineffective, leading to short survival. ${ }^{41}$

After almost one decade of clinical experience with CD19-directed CARs, ${ }^{21}{ }^{42}$ CAR T cells have become an available treatment option for patients with CD19-positive lymphoid malignancies. Second-generation CAR T cells targeting CD19 have been approved by the US Food and Drug Administration (FDA) and the European Medicines Agency (EMA) in October 2017 and August 2018, respectively: axicabtagene ciloleucel (Yescarta) carrying CD28 as a costimulatory domain is approved for patients with DLBCL, transformed FL and primary mediastinal B cell lymphoma who have not responded to or who have relapsed after at least two treatment lines. Tisagenlecleucel (Kymriah) carrying $4-1 \mathrm{BB}$ as a costimulatory domain is approved for patients up to 25 years of age with ALL that is refractory or in second or later relapse as well as adult patients with $\mathrm{r} / \mathrm{r}$ DLBCL after two or more lines of systemic therapy.

\section{How to speed up CAR T cell therapy in Europe?}

Axicabtagene ciloleucel and tisagenlecleucel were recently approved by the EMA. However, it will still take some time until all logistic and legal issues will be cleared. All of these products are currently produced outside of Europe and therefore both leukapheresis and CAR T cell products need to be cryopreserved and shipped to the manufacturing facility oversea and back. Moreover, $>90 \%$ of CAR T cell trials are performed outside Europe, that is, in the USA and the P.R. China. ${ }^{43}$ This disparity in the geographic location is due to (1) lacking access to GMP facilities given that CAR T cell manufacturing in the European Union (EU) requires GMP compliance on an industrial level, (2) complex authorisation processes and (3) differences in the respective regulatory requirements within individual EU states. In Germany, at present only four clinical CAR $\mathrm{T}$ cell trials are registered, all being industry-driven (NCT02445222 [Novartis], NCT02348216 [Kite/Gilead], NCT03484702 [Celgene] and NCT02445248 [Novartis]) (clinicaltrials.gov search on 2 September 2018 for terms 'CAR T cells+Germany').

Preparation for approval of the current HD-CAR-1 trial took approximately 2.5 years. Whereas in the USA, the FDA is the only authority regulating CAR T cell manufacturing as well as clinical administration, CAR $\mathrm{T}$ cell therapy in Germany involves several regulatory institutions: federal (Paul-Ehrlich Institute [PEI]) as well as local (Regierungspraesidium $[\mathrm{RP}]$ ) regulatory authorities authorise and survey clinical trials and CAR $\mathrm{T}$ cell manufacturing in accordance with GMP standards. Moreover, the local EC monitors patient safety. Although clinical trial regulation for Europe has been updated in 2014 and the authorisation process is aimed to be harmonised in the near future, current authorisation requires simultaneous submission of applications to the distinct authorities: for HD-CAR-1, initial applications were submitted in September 2016 to the PEI and the EC of the University of Heidelberg. Approval from the EC, the PEI competent authority and the RP local authority were granted in October 2017, September and August 2018, respectively. HD-CAR-1 was initiated on 7 September 2018.

\section{Why do we need this trial?}

The majority of clinical CAR $\mathrm{T}$ cell trials have used second-generation CAR constructs incorporating either CD28 or 4-1BB. CD28 has been associated with robust CAR $\mathrm{T}$ cell expansion, rapid tumour elimination in vitro ${ }^{44-46}$ and persistence up to 3 months in treated patients. ${ }^{132} 24$ $4-1 \mathrm{BB}$, in turn, has displayed longer in vitro ${ }^{47} 48$ and in vivo persistence $^{495}$ when compared with CD28, has been associated with reduced CAR $\mathrm{T}$ cell exhaustion ${ }^{51}$ and been detectable for more than 5 years in patients treated with CD19-directed CAR T cells. ${ }^{14}{ }^{23}$ It has been shown that $4-1 \mathrm{BB}$ costimulation promotes central memory CAR $\mathrm{T}$ cells, diminishes exhaustion and mediates a metabolic profile that results in enhanced CAR T cells persistence. ${ }^{4451}$ In contrast, $\mathrm{CD} 28$ costimulation results in differentiation into effector memory CAR T cells with short-lived glycolysis-based metabolism. ${ }^{44}$ Based on these distinct characteristics, third-generation CARs comprising both these elements might display short-term efficacy (CD28) as well as longterm persistence (4-1BB). Nonetheless, also reduced efficacy and increased levels of apoptosis have been related to third-generation CAR T cells ${ }^{52}$ highlighting the need for further clinical evaluation.

Turtle $e t a l^{16}$ demonstrated that chemotherapy with flu and cyc preceding CAR $\mathrm{T}$ cell administration improved the outcome of treated patients. In contrast to previous trials, flu and cyc conditioning will be consequently incorporated within the HD-CAR-1 trial (see figure 3). Furthermore, most of the trials including the pivotal CD19-directed CAR T cell trials JULIET and ZUMA-1/$2^{18}$ excluded patients after allogeneic stem cell transplantation (alloSCT). HD-CAR-1 allows treatment of these 
patients since this patient population is particularly in need of novel treatment options.

Two clinical trials using third-generation CARs targeting CD19 have been recently published. ${ }^{53} 54$ The first trial included heavily pretreated leukaemia and lymphoma patients displaying significant comorbidities. Following treatment with CAR T cells comprising CD28 and 4-1BB costimulatory domains, responses could be achieved in $40 \%$ of these patients. ${ }^{53}$ Several conceptual differences of this trial and our own study initiated in September 2018 exist, that is: (1) only $70 \%$ of patients received lymphodepleting chemotherapy consisting of low-dose cycand flu, (2) CAR T cell manufacturing differs in terms of stimulation of CAR T cell culture (IL-2 vs IL-7/-15), (3) only adult patients were included, whereas our trial will include paediatric patients also.

The second trial investigated the benefit of third-generation CAR $\mathrm{T}$ cells administering simultaneously second-generation (containing only CD28 as costimulatory domain) and third-generation CAR $\mathrm{T}$ cells (CD28 and 4-1BB; identical to the HD-CAR-1 vector) to NHL patients. Responses in patients with $\mathrm{r} / \mathrm{r}$ disease were achieved in $54 \%$ of treated patients. Compared with cells transduced with the second-generation CAR vector, third-generation CAR T cells displayed superior expansion and longer persistence, particularly in patients with low disease burden and low levels of circulating B cells. ${ }^{54}$ Nonetheless, the number of patients treated with third-generation CAR $T$ cells remains low, and further studies are required for detailed evaluation of third-generation CD19-directed CAR T cells.

HD-CAR-1 of the University Hospital Heidelberg is the first CAR T cell IIT in Germany and evaluates third-generation CD19.CAR $\mathrm{T}$ cell administration to adult and paediatric patients with $\mathrm{r} / \mathrm{r}$ ALL as well as patients with $\mathrm{r} / \mathrm{r}$ CLL or other NHL. Given that leukapheresis, CD19. CAR T cell manufacturing, administration, patient monitoring and follow-up are performed in-house, independence of transport systems and production sites outside the University Hospital Heidelberg or even Europe is provided. Additionally, close interaction with the PEI, $\mathrm{RP}$ and academic discussion and exchange support and promote treatment with CAR T cells and other novel cell therapies in Germany and Europe.

\section{Author affiliations}

${ }^{1}$ Department of Internal Medicine V, Heidelberg University Hospital, Heidelberg, Germany

${ }^{2}$ German Cancer Consortium (DKTK), National Centre for Tumour Diseases (NCT), Heidelberg, Germany

${ }^{3}$ Department of Pediatric Hematology, Oncology and Immunology, Children's Hospital, Heidelberg University Hospital, Heidelberg, Germany

${ }^{4}$ Institute of Transfusion Medicine and Immunology, Medical Faculty Mannheim, Heidelberg University, Mannheim, Germany

Acknowledgements We thank $\mathrm{M}$ Hinkelbein for support with editing text and management of references. We thank Professor Malcolm Brenner, Baylor's College of Medicine, for vector design and GMP production of the retroviral vector as well as for his continuous support during the last $2 \frac{1}{2}$ years and hopefully beyond.
Contributors $\mathrm{MS}$ is the principle investigator $(\mathrm{PI}), \mathrm{PD}$ is the deputy $\mathrm{PI}$ of the HD-CAR-1 clinical trial. MS, M-LS, PD, LS, AS, JK, ADH, CM-T, PW, AKul and SH reviewed the protocol of the trial. MS, M-LS, AS, LS, BN, JK, AH-K, AKul and PD were involved in the process of obtaining approval for the clinical trial from the ethical committee and the competent authority. MS, AS, BN, UG, AH-K, BM and AKun worked on the Good Manufacturing Practice (GMP) CD19.CART cell generation protocol and its approval from the local authority for obtaining the manufacturing license. M-LS, LS, MS and PD wrote the study protocol. M-LS wrote the primary manuscript. All authors critically reviewed the manuscript.

Funding This work has been generously supported by the Ministry of Science, Research and Arts of Baden-Württemberg 'Brückeninstitutionen - Initiative', by the National Center of Tumor Diseases (NCT), by the German Cancer Research Institute (DKFZ), by the Jochen Siebeneicher Foundation and by a personal donation from Dr h c Karl Schlecht.

Competing interests None declared.

Patient consent for publication Not required.

Ethics approval Ethical approval and approvals from the local and federal competent authorities were granted. HD-CAR-1 trial protocol received Institutional Review Board approval from the EC of the University of Heidelberg in October 2017 (AFmu-405/2017).

Provenance and peer review Not commissioned; externally peer reviewed.

Open access This is an open access article distributed in accordance with the Creative Commons Attribution Non Commercial (CC BY-NC 4.0) license, which permits others to distribute, remix, adapt, build upon this work non-commercially, and license their derivative works on different terms, provided the original work is properly cited, appropriate credit is given, any changes made indicated, and the use is non-commercial. See: http://creativecommons.org/licenses/by-nc/4.0/.

\section{REFERENCES}

1. Poon LM, Hamdi A, Saliba R, et al. Outcomes of adults with acute lymphoblastic leukemia relapsing after allogeneic hematopoietic stem cell transplantation. Biol Blood Marrow Transplant 2013;19:1059-64.

2. Roberts AW, Davids MS, Pagel JM, et al. Targeting BCL2 with venetoclax in relapsed chronic lymphocytic leukemia. $N$ Engl J Med 2016;374:311-22.

3. Byrd JC, Furman RR, Coutre SE, et al. Targeting BTK with ibrutinib in relapsed chronic lymphocytic leukemia. $N$ Engl J Med 2013;369:32-42.

4. Stilgenbauer S, Eichhorst B, Schetelig J, et al. Venetoclax in relapsed or refractory chronic lymphocytic leukaemia with $17 \mathrm{p}$ deletion: a multicentre, open-label, phase 2 study. Lancet Oncol 2016;17:768-78.

5. Jain P, Keating M, Wierda W, et al. Outcomes of patients with chronic lymphocytic leukemia after discontinuing ibrutinib. Blood 2015;125:2062-7.

6. Crump M, Neelapu SS, Farooq U, et al. Outcomes in refractory diffuse large B-cell lymphoma: results from the international SCHOLAR-1 study. Blood 2017;130:1800-8.

7. Salles G, Schuster SJ, de Vos S, et al. Efficacy and safety of idelalisib in patients with relapsed, rituximab- and alkylating agent-refractory follicular lymphoma: a subgroup analysis of a phase 2 study. Haematologica 2017;102:e156-e59.

8. Dreyling $M$, Jurczak $W$, Jerkeman $M$, et al. Ibrutinib versus temsirolimus in patients with relapsed or refractory mantle-cell lymphoma: an international, randomised, open-label, phase 3 study. Lancet 2016;387:770-8.

9. Schubert ML, Hückelhoven A, Hoffmann JM, et al. Chimeric antigen receptor T Cell therapy targeting CD19-positive leukemia and lymphoma in the context of stem cell transplantation. Hum Gene Ther 2016;27:758-71.

10. Maude SL, Laetsch TW, Buechner J, et al. Tisagenlecleucel in children and young adults with B-Cell lymphoblastic leukemia. $N$ Engl J Med 2018;378:439-48.

11. Gardner RA, Finney $O$, Annesley C, et al. Intent-to-treat leukemia remission by CD19 CAR T cells of defined formulation and dose in children and young adults. Blood 2017;129:3322-31.

12. Park JH, Rivière I, Gonen M, et al. Long-Term Follow-up of CD19 CAR therapy in acute lymphoblastic leukemia. N Engl J Med 2018;378:449-59.

13. Davila ML, Riviere I, Wang X, et al. Efficacy and toxicity management of 19-28z CAR T cell therapy in B cell acute lymphoblastic leukemia. Sci Transl Med 2014;6:224ra25. 
14. Porter DL, Hwang WT, Frey NV, et al. Chimeric antigen receptor T cells persist and induce sustained remissions in relapsed refractory chronic lymphocytic leukemia. Sci Transl Med 2015;7:303ra139.

15. Turtle CJ, Hay KA, Hanafi LA, et al. Durable molecular remissions in chronic lymphocytic leukemia treated with CD19-specific chimeric antigen receptor-modified T Cells after failure of ibrutinib. J Clin Oncol 2017;35:3010-20.

16. Turtle CJ, Hanafi L-A, Berger C, et al. Immunotherapy of nonHodgkin's lymphoma with a defined ratio of CD8<sup $>+</$ sup $>$ and $\mathrm{CD} 4<$ sup $>+</$ sup $>$ CD19-specific chimeric antigen receptormodified T cells. Science Translational Medicine 2016;8355.

17. Schuster SJ, Svoboda J, Chong EA, et al. Chimeric antigen receptor T Cells in refractory B-Cell lymphomas. N Engl J Med 2017;377:2545-54.

18. Neelapu SS, Locke FL, Bartlett NL, et al. Axicabtagene ciloleucel CAR T-Cell therapy in refractory large B-Cell lymphoma. N Engl $J$ Med 2017;377:2531-44.

19. Kochenderfer JN, Somerville RPT, Lu T, et al. Long-duration complete remissions of diffuse large B Cell lymphoma after Anti-CD19 chimeric antigen receptor T Cell therapy. Mol Ther 2017;25:2245-53.

20. Eshhar Z, Waks T, Gross G, et al. Specific activation and targeting of cytotoxic lymphocytes through chimeric single chains consisting of antibody-binding domains and the gamma or zeta subunits of the immunoglobulin and T-cell receptors. Proc Natl Acad Sci U S A 1993;90:720-4.

21. Jensen MC, Popplewell L, Cooper LJ, et al. Antitransgene rejection responses contribute to attenuated persistence of adoptively transferred CD20/CD19-specific chimeric antigen receptor redirected T cells in humans. Biol Blood Marrow Transplant 2010;16:1245-56.

22. Brentjens RJ, Davila ML, Riviere I, et al. CD19-targeted T cells rapidly induce molecular remissions in adults with chemotherapy-refractory acute lymphoblastic leukemia. Sci Transl Med 2013;5:177ra38.

23. Maude SL, Frey N, Shaw PA, et al. Chimeric antigen receptor $\mathrm{T}$ cells for sustained remissions in leukemia. $N$ Engl $\mathrm{J}$ Med 2014;371:1507-17.

24. Lee DW, Kochenderfer JN, Stetler-Stevenson M, et al. T cells expressing CD19 chimeric antigen receptors for acute lymphoblastic leukaemia in children and young adults: a phase 1 dose-escalation trial. Lancet 2015;385:517-28.

25. Tammana S, Huang X, Wong M, et al. 4-1BB and CD28 signaling plays a synergistic role in redirecting umbilical cord blood T cells against B-cell malignancies. Hum Gene Ther 2010;21:75-86.

26. Zhong XS, Matsushita M, Plotkin J, et al. Chimeric antigen receptors combining 4-1BB and CD28 signaling domains augment PI3kinase/ $\mathrm{AKT} / \mathrm{Bcl}-\mathrm{XL}$ activation and CD8+ T cell-mediated tumor eradication. Mol Ther 2010;18:413-20.

27. Karlsson H, Svensson E, Gigg C, et al. Evaluation of intracellular signaling downstream chimeric antigen receptors. PLoS One 2015;10:e0144787.

28. Gomes da Silva D, Mukherjee M, Srinivasan M, et al. Direct comparison of in vivo fate of second and third-generation CD19Specific Chimeric Antigen Receptor (CAR)-T Cells in Patients with B-Cell Lymphoma: Reversal of Toxicity from Tonic Signaling. Blood 2016;128:1851-51.

29. Pule MA, Savoldo B, Myers GD, et al. Virus-specific T cells engineered to coexpress tumor-specific receptors: persistence and antitumor activity in individuals with neuroblastoma. Nat Med 2008;14:1264-70.

30. Rossig C, Bollard CM, Nuchtern JG, et al. Epstein-Barr virusspecific human $T$ lymphocytes expressing antitumor chimeric T-cell receptors: potential for improved immunotherapy. Blood 2002;99:2009-16.

31. Lee DW, Gardner R, Porter DL, et al. Current concepts in the diagnosis and management of cytokine release syndrome. Blood 2014;124:188-95.

32. Cairo MS, Bishop M. Tumour lysis syndrome: new therapeutic strategies and classification. Br J Haematol 2004;127:3-11.

33. Hunger SP, Lu X, Devidas M, et al. Improved survival for children and adolescents with acute lymphoblastic leukemia between 1990 and 2005: a report from the children's oncology group. J Clin Oncol 2012;30:1663-9

34. Sive Jl, Buck G, Fielding A, et al. Outcomes in older adults with acute lymphoblastic leukaemia (ALL): results from the international MRC UKALL XII/ECOG2993 trial. Br J Haematol 2012;157:463-71.

35. Poon LM, Bassett R, Rondon G, et al. Outcomes of second allogeneic hematopoietic stem cell transplantation for patients with acute lymphoblastic leukemia. Bone Marrow Transplant 2013;48:666-70.

36. Hallek M, Fischer K, Fingerle-Rowson G, et al. Addition of rituximab to fludarabine and cyclophosphamide in patients with chronic lymphocytic leukaemia: a randomised, open-label, phase 3 trial. Lancet 2010;376:1164-74

37. Pfreundschuh M, Trümper L, Osterborg A, et al. CHOP-like chemotherapy plus rituximab versus $\mathrm{CHOP}$-like chemotherapy alone in young patients with good-prognosis diffuse large-Bcell lymphoma: a randomised controlled trial by the MabThera International Trial (MInT) Group. Lancet Oncol 2006;7:379-91.

38. Salles G, Seymour JF, Offner F, et al. Rituximab maintenance for 2 years in patients with high tumour burden follicular lymphoma responding to rituximab plus chemotherapy (PRIMA): a phase 3, randomised controlled trial. Lancet 2011;377:42-51.

39. Wang ML, Rule S, Martin P, et al. Targeting BTK with ibrutinib in relapsed or refractory mantle-cell lymphoma. $N$ Engl $J$ Med 2013;369:507-16.

40. Furman RR, Sharman JP, Coutre SE, et al. Idelalisib and rituximab in relapsed chronic lymphocytic leukemia. N Engl J Med 2014;370:997-1007.

41. Martin P, Maddocks K, Leonard JP, et al. Postibrutinib outcomes in patients with mantle cell lymphoma. Blood 2016;127:1559-63.

42. Kochenderfer JN, Wilson WH, Janik JE, et al. Eradication of $B$-lineage cells and regression of lymphoma in a patient treated with autologous T cells genetically engineered to recognize CD19. Blood 2010;116:4099-102.

43. Hartmann J, Schüßler-Lenz M, Bondanza A, et al. Clinical development of CAR T cells-challenges and opportunities in translating innovative treatment concepts. EMBO Mol Med 2017;9:1183-97.

44. Kawalekar OU, O'Connor RS, Fraietta JA, et al. Distinct signaling of coreceptors regulates specific metabolism pathways and impacts memory development in CAR T Cells. Immunity 2016:44:380-90.

45. Kowolik CM, Topp MS, Gonzalez S, et al. CD28 costimulation provided through a CD19-specific chimeric antigen receptor enhances in vivo persistence and antitumor efficacy of adoptively transferred T cells. Cancer Res 2006;66:10995-1004.

46. Loskog A, Giandomenico V, Rossig C, et al. Addition of the CD28 signaling domain to chimeric T-cell receptors enhances chimeric T-cell resistance to T regulatory cells. Leukemia 2006;20:1819-28.

47. Finney HM, Akbar AN, Lawson AD. Activation of resting human primary T cells with chimeric receptors: costimulation from CD28, inducible costimulator, CD134, and CD137 in series with signals from the TCR zeta chain. $J$ Immunol 2004;172:104-13.

48. Wang J, Jensen M, Lin Y, et al. Optimizing adoptive polyclonal $\mathrm{T}$ cell immunotherapy of lymphomas, using a chimeric $T$ cell receptor possessing CD28 and CD137 costimulatory domains. Hum Gene Ther 2007;18:712-25.

49. Zhao Z, Condomines M, van der Stegen SJC, et al. Structural design of engineered costimulation determines tumor rejection kinetics and persistence of CAR T cells. Cancer Cell 2015;28:415-28.

50. Milone MC, Fish JD, Carpenito C, et al. Chimeric receptors containing CD137 signal transduction domains mediate enhanced survival of T cells and increased antileukemic efficacy in vivo. Mol Ther 2009;17:1453-64

51. Long AH, Haso WM, Shern JF, et al. 4-1BB costimulation ameliorates $\mathrm{T}$ cell exhaustion induced by tonic signaling of chimeric antigen receptors. Nat Med 2015;21:581-90.

52. Künkele A, Johnson AJ, Rolczynski LS, et al. Functional tuning of CARs reveals signaling threshold above which CD8+ CTL antitumor potency is attenuated due to Cell fas-fasl-dependent AICD. Cancer Immunol Res 2015;3:368-79.

53. Enblad G, Karlsson H, Gammelgård G, et al. A Phase I/lla Trial Using CD19-Targeted Third-Generation CAR T cells for lymphoma and leukemia. Clin Cancer Res 2018;24:6185-94.

54. Ramos CA, Rouce R, Robertson CS, et al. In Vivo fate and activity of second- versus third-generation CD19-Specific CAR-T Cells in B Cell non-hodgkin's lymphomas. Mol Ther 2018;26:2727-37.

55. Savoldo B, Ramos CA, Liu E, et al. CD28 costimulation improves expansion and persistence of chimeric antigen receptor-modified $\mathrm{T}$ cells in lymphoma patients. $J$ Clin Invest 2011:121:1822-6.

56. Brentjens RJ, Rivière I, Park JH, et al. Safety and persistence of adoptively transferred autologous CD19-targeted T cells in patients with relapsed or chemotherapy refractory B-cell leukemias. Blood 2011;118:4817-28.

57. Kalos M, Levine BL, Porter DL, et al. T cells with chimeric antigen receptors have potent antitumor effects and can establish memory in patients with advanced leukemia. Sci Trans/ Med 2011;3:ra73: 95ra73.

58. Porter DL, Levine BL, Kalos M, et al. Chimeric antigen receptormodified T cells in chronic lymphoid leukemia. $N$ Engl J Med 2011;365:725-33. 
59. Kochenderfer JN, Dudley ME, Feldman SA, et al. B-cell depletion and remissions of malignancy along with cytokine-associated toxicity in a clinical trial of anti-CD19 chimeric-antigen-receptor-transduced T cells. Blood 2012;119:2709-20.

60. Kochenderfer JN, Rosenberg SA. Treating B-cell cancer with T cells expressing anti-CD19 chimeric antigen receptors. Nat Rev Clin Oncol 2013;10:267-76.

61. Cruz CR, Micklethwaite KP, Savoldo B, et al. Infusion of donorderived CD19-redirected virus-specific T cells for B-cell malignancies relapsed after allogeneic stem cell transplant: a phase 1 study. Blood 2013;122:2965-73.

62. Grupp SA, Kalos M, Barrett D, et al. Chimeric antigen receptormodified T cells for acute lymphoid leukemia. $N$ Engl J Med 2013;368:1509-18.

63. Kochenderfer JN, Dudley ME, Kassim SH, et al. Chemotherapyrefractory diffuse large B-cell lymphoma and indolent B-cell malignancies can be effectively treated with autologous T cells expressing an anti-CD19 chimeric antigen receptor. J Clin Oncol 2015;33:540-9.

64. Brudno JN, Somerville RP, Shi V, et al. Allogeneic T Cells that express an Anti-CD19 Chimeric antigen receptor induce remissions of B-Cell malignancies that progress after allogeneic hematopoietic stem-cell transplantation without causing graft-versus-host disease. J Clin Oncol 2016;34:1112-21.

65. Dai $\mathrm{H}$, Zhang W, Li X, et al. Tolerance and efficacy of autologous or donor-derived T cells expressing CD19 chimeric antigen receptors in adult B-ALL with extramedullary leukemia. Oncoimmunology 2015;4:e1027469.
66. Zhu YM, Wu Z, Tan YP, et al. Anti-CD19 chimeric antigen receptor T-cell therapy for adult philadelphia chromosome-positive acute lymphoblastic leukemia: two case reports. Medicine 2016;95:e5676.

67. Turtle CJ, Hanafi LA, Berger C, et al. Immunotherapy of nonhodgkin's lymphoma with a defined ratio of CD8+ and CD4+ CD19specific chimeric antigen receptor-modified T cells. Sci Transl Med 2016;8:ra116.

68. Wang X, Popplewell LL, Wagner JR, et al. Phase 1 studies of central memory-derived CD19 CAR T-cell therapy following autologous HSCT in patients with B-cell NHL. Blood 2016;127:2980-90.

69. Kebriaei P, Singh H, Huls MH, et al. Phase I trials using sleeping beauty to generate CD19-specific CAR T cells. J Clin Invest 2016;126:3363-76.

70. Locke FL, Neelapu SS, Bartlett NL, et al. Phase 1 results of ZUMA-1: a multicenter study of KTE-C19 Anti-CD19 CAR T Cell Therapy in refractory aggressive lymphoma. Mol Ther 2017;25:285-95.

71. Hu Y, Wu Z, Luo Y, et al. Potent anti-leukemia activities of Chimeric antigen receptor-modified $t$ cells against cd19 in chinese patients with relapsed/refractory acute lymphocytic leukemia. Clin Cancer Res 2017;23:3297-306.

72. Li S, Zhang J, Wang M, et al. Treatment of acute lymphoblastic leukaemia with the second generation of CD19 CAR-T containing either CD28 or 4-1BB. Br J Haematol 2018;181:360-71.

73. Cao J, Wang G, Cheng $\mathrm{H}$, et al. Potent anti-leukemia activities of humanized CD19-targeted Chimeric antigen receptor T (CAR-T) cells in patients with relapsed/refractory acute lymphoblastic leukemia. Am J Hematol 2018;93:851-8. 